\title{
Eficiência de Utilização da Energia Metabolizável para Ganho de Peso e Exigências de Energia Metabolizável, Nutrientes Digestíveis Totais e Proteína Metabolizável de Bezerros da Raça Holandesa ${ }^{1}$
}

\section{Ricardo Dias Signoretti ${ }^{2}$, José Fernando Coelho da Silva ${ }^{3}$, Sebastião de Campos Valadares Filho $^{3}$, José Carlos Pereira ${ }^{3}$, Gherman Garcia Leal de Araújo ${ }^{5}$, Paulo Roberto Cecon ${ }^{4}$, Augusto César de Queiroz ${ }^{3}$}

\begin{abstract}
RESUMO - Este trabalho visou avaliar os efeitos de diferentes níveis de volumoso nas dietas, sobre a eficiência de utilização de energia metabolizável (EM) para mantença e ganho de peso e as exigências de EM, nutrientes digestíveis totais (NDT) e proteína metabolizável (PM). Quarenta e quatro bezerros Holandeses, puros por cruzamento, não-castrados, com idade média de 60 dias e peso vivo inicial de $78 \mathrm{~kg}$ foram usados. Oito animais foram abatidos ao início do experimento, como referência. Os 36 animais restantes foram distribuídos nos tratamentos, em delineamento inteiramente casualizado, em quatro grupos de nove animais, de acordo com o nível de volumoso nas dietas: 10, 25, 40, e 55\%, na base da MS, usando-se feno de capim coast-cross (Cynodon dactylon), fubá de milho e farelo de soja, os quais constituíram dietas com aproximadamente $16 \%$ de PB. Cinco animais de cada tratamento foram abatidos quando atingiram $190 \pm 10 \mathrm{~kg}$ e quatro, quando atingiram $300 \pm 10 \mathrm{~kg}$. As concentrações de energia líquida das dietas e as eficiências de utilização da EM para mantença e ganho de peso foram calculadas. As eficiências de utilização de EM para ganho de peso foram estimadas, por meio de análise de regressão, entre a energia líquida para ganho $(\mathrm{ELg})$, em função da EM das dietas. As exigências médias diárias de EM, nutrientes digestíveis totais (NDT) e proteína metabolizável (PM) foram estimadas. As exigências de EM para ganho de $1 \mathrm{~kg}$ de peso corporal vazio aumentaram, à medida que se elevou o PCVZ dos animais. As eficiências de utilização da energia metabolizável para ganho de peso em: 0,45; 0,40; 0,40 e 0,39, respectivamente, para as concentrações de 2,98; 2,76;2,64 e 2,53 Mcal/kg de MS, obtidas para os níveis de 10; 25; 40 e 55\% de volumoso nas dietas foram estimadas. As exigências médias totais de EM e de NDT para animais de 100, 200 e $300 \mathrm{~kg}$ de peso vivo foram de 10,06; 14,45 e 18,12 Mcal/dia e 2,79; 4,00 e 5,02 kg/dia, respectivamente. A eficiência de utilização da EM para ganho foi maior para dietas com menor nível de volumoso.
\end{abstract}

Palavras-chave: bezerro holandês, eficiência, energia metabolizável, nível de volumoso, proteína

\section{Efficiency of Metabolizable Energy Utilization for Weight Gain and Requirements of Metabolizable Energy, Total Digestible Nutrients and Metabolizable Protein of Holstein Bull Calves}

\footnotetext{
ABSTRACT - This work was to evaluate the effects of different forage levels in the diet on the efficiency of metabolizable energy (ME) utilization for maintenance and weight gain, and the requirements of ME, total digestible nutrients (TDN) and metabolizable protein (MP). Forty-four pure Holstein bulls calves, 60 days old with initial average live weight (LW) of $78 \mathrm{~kg}$ were used. Eight reference animals were slaughtered at the beginning of the feeding trial. The remaining 36 animals were allotted in the treatments in a complete randomized experimental design, in four groups of nine animals, in function of forage levels in the diet: 10, 25, 40 and 55\%, on the DM basis, using chopped coast-cross (Cynodon dactylon) grass, ground corn and soybean meal, which constitute diets with approximately $16 \% \mathrm{CP}$. Five animals from each treatment were slaughtered with $190+10 \mathrm{~kg} \mathrm{LW}$ and four with $300+10 \mathrm{~kg} \mathrm{LW}$. The net energy (NE) contents of rations and the efficiency of utilization of ME for maintenance and weight gain were calculated. The efficiencies of ME for weight gain were estimated by regression analysis, between net energy for weight gain in function of dietary ME. The daily requirements of ME, TDN and MP were estimated. ME requirements for $1 \mathrm{~kg}$ of empty body weight (EBW) gain increased with the EBW of the animals. The efficiency of EM utilization for weight gain were estimated as: $.45, .40, .40$ and .39 , respectively for EM concentrations of 2.98, 2.76, 2.64, and $2.53 \mathrm{Mcal} / \mathrm{kg}$ of DM, obtained for the diets with $10,25,40$, and $55 \%$ of forage in the diets. The mean requirements of ME and TDN for animals with 100,200 and $300 \mathrm{~kg} L W$ were $10.06,14.45$, and $18.12 \mathrm{Mcal} /$ day and of $2.79,4.00$ and $5.02 \mathrm{~kg}$ /day, respectively. The efficiency of ME utilization for weight gain was greater for diets with low levels of forage.

Key Words: Holstein calf, efficiency, metabolizable energy, forage level, protein

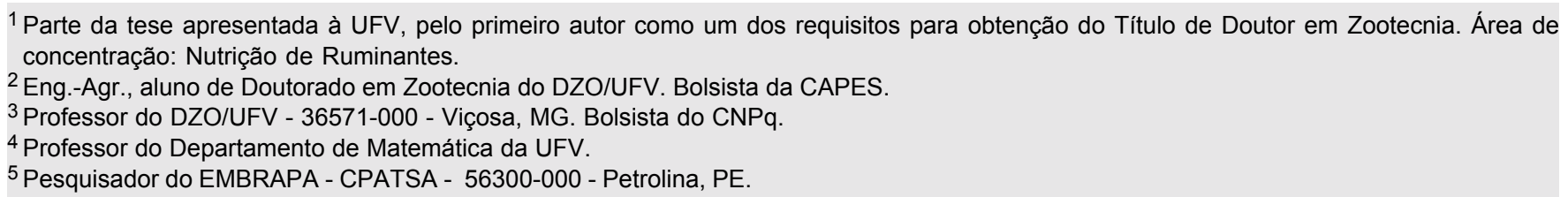




\section{Introdução}

$\mathrm{O}$ valor de um alimento usado na dieta de um animal baseia-se, principalmente, na quantidade de energia que ele será capaz de suprir. Entre as diversas formas de se expressar a energia, a mais comum da energia alimentícia é por meio dos nutrientes digestíveis totais (NDT), seguindo-se da energia digestível(ED), da energia metabolizável (EM) e da energia líquida (EL).

As exigências energéticas dos animais são as mais difíceis de serem determinadas, porque a eficiência de utilização de energia para os diversos processos fisiológicos, como mantença, crescimento, engorda e lactação, é variável, além de existirem muitos outros fatores que interferem, como o clima, o trabalho muscular realizado pelo animal e, principalmente, a concentração de energia metabolizável no alimento ou dieta, uma vez que, quanto maior a concentração de EM, maior será a eficiência de sua utilização para mantença e ganho (COELHO DA SILVA e LEÃO, 1979).

O estudo do balanço energético possibilita avaliar o teor energético de alimentos, as exigências de energia dos animais e as eficiências de utilização da EM para mantença e ganho de peso. As variações no balanço energético são influenciadas pelo nível de consumo e pelas interações dos alimentos (efeito associativo). A adição de concentrado em dietas à base de volumoso aumenta parcialmente a eficiência, em virtude da depressão na produção de metano, da redução da ruminação e da diminuição do incremento calórico. Além disso, os alimentos volumosos de pior qualidade são menos eficientes que os de melhor qualidade (VAN SOEST, 1994).

Na prática, a determinação da eficiência de utilização de energia para ruminantes é feita por intermédio da técnica de abate comparativo e, ou, balanço calorimétrico, em que os dados são avaliados por modelos e equações matemáticas. O cálculo da eficiência de utilização de EM para mantença ou ganho de peso é realizado pela relação entre a ELm e a EM da dieta e entre ELg e a EM da dieta.

O conhecimento da relação entre a deposição de energia e o ganho de peso é necessário para utilizar o sistema de energia líquida na formulação de dietas, para taxas de ganho específicas, ou para determinar a taxa de ganho do animal recebendo quantidade conhecida de um alimento específico ou mistura de alimentos. Todavia, o conteúdo de energia para ganho é influenciado pelo sexo, pela classe, pela raça e, em menor escala, pelo uso de hormônios adjuvantes (GARRETT, 1980).
A eficiência de utilização de EM para produção é influenciada, principalmente, pelas características da dieta: o valor comparativo de volumosos e concentrados, o teor de fibra, o tempo de ingestão e ruminação e as relações de ácidos graxos voláteis no rúmen (VAN SOEST, 1994).

O AFRC (1993) considera que o requerimento de EM para crescimento diário $(\mathrm{MJ} / \mathrm{dia})$ é igual ao produto do ganho diário $(\mathrm{kg} / \mathrm{dia})$ pelo valor energético, dividido pela eficiência de utilização de EM para ganho (kf). O valor energético do ganho está em função do peso corporal e de seu ganho de peso, com correções para precocidade de raça e sexo.

Segundo o NRC (1984), a eficiência de utilização de EM para mantença variou de 57,6 a 68,6\% e, para ganho, de 29,6 a 47,3\%, quando a concentração de EM da dieta variou de 2,0 a 3,2 Mcal/kg de MS.

A eficiência de utilização para ganho não é constante para pesos corporais (maturidade) e taxas de ganho. O INRA (1988), citado pelo NRC (1996), assumiu redução na eficiência com aumento do peso corporal de bovinos em crescimento.

A eficiência de utilização de EM para síntese de proteína e gordura em ruminantes ainda não foi definida com segurança. GARRETT (1980) relatou que a eficiência de utilização de EM na síntese de proteína variou de 10 a $42 \%$ e na síntese de gordura, de 60 a $80 \%$.

As exigências de proteína dos ruminantes são atendidas pelos aminoácidos absorvidos no intestino delgado, denominadas exigências de proteína metabolizável (PM). A proteína que chega ao intestino delgado consiste de fração microbiana, da fração dietética não-degradada no rúmen e da proteína endógena (VALADARES FILHO, 1997). Este conceito de PM introduzido no cálculo das exigências pelo AFRC (1993) é definido como a proteína verdadeira digestível total disponível para o metabolismo animal, após digestão do alimento e absorção, a partir do trato gastrointestinal. $\mathrm{O}$ requerimento de mantença para PM é de 2,30 kg $\mathrm{kg}^{0,75}$ (g/dia), segundo AFRC (1993).

O cálculo do requerimento de PM utilizado pelo NRC $(1984,1996)$ baseou-se no método fatorial, incluindo perdas metabólicas fecal, perdas urinárias, perdas por descamação de pele (pêlos), crescimento, crescimento fetal e leite. As perdas metabólicas fecal e urinária e a descamação de pele representam os requerimentos de mantença, que é de $3,80 \mathrm{~kg}^{0,75}$ (g/dia), segundo NRC (1996).

A eficiência de síntese de proteína microbiana será máxima, quando a degradabilidade da proteína 
216 Rev. bras. zootec.

dietética atender exatamente às necessidades microbianas, desde que não haja limitação da fonte energética e outros fatores. No entanto, a eficiência de utilização de proteína nos tecidos será máxima, se a soma da proteína microbiana e da proteína dietética não-degradada no rúmen atender às exigências dos tecidos, em termos quantitativos e qualitativos. Assim, a eficiência de utilização de proteína microbiana será máxima, se as eficiências em nível de rúmen e tecido forem máximas (WALDO e GLEN, 1981).

OLD e GARRETT (1984) verificaram redução na eficiência de utilização de proteína, à medida que se elevou o teor protéico da dieta. Observaram ainda que, para o mesmo consumo de EM, houve maiores acúmulos de proteína em animais de maturidade tardia (Raça Charolesa) que nos de maturidade precoce (Raça Holandesa).

Conhecendo-se as exigências líquidas de mantença e produção e levando-se em consideração os fatores de eficiência de utilização de energia e proteína do alimento para mantença e produção, obtêm-se as exigências dietéticas.

Apesar de existirem alguns trabalhos publicados sobre as exigências nutricionais de bovinos no Brasil, observa-se que poucos determinaram os fatores de conversão das exigências líquidas em dietéticas. Assim, o objetivo deste trabalho foi determinar a eficiência de utilização da energia metabolizável para ganho de peso e as exigências de EM, NDT e PM para mantença e ganho de peso de bezerros da raça Holandesa, não-castrados, alimentados com dietas contendo diferentes níveis de volumoso.

\section{Material e Métodos}

O local do experimento, as dietas utilizadas, a proporção de ingredientes nas mesmas, o manejo e os animais utilizados, os ensaios de digestibilidade, os procedimentos de abate e amostragens de tecido animal e vegetal, as análises químicas, o delineamento experimental e as análises estatísticas foram descritos por SIGNORETTI et al. (1999 a,b).

As concentrações de energia líquida das dietas foram calculadas conforme HARRIS (1970).

A ingestão de matéria seca (MS), suficiente para manter o equilíbrio de energia (produção de calor = ingestão de energia metabolizável), foi calculada dividindo-se o consumo de energia metabolizável (EM) suficiente para mantença $\left(178 \mathrm{kcal} / \mathrm{kg}^{0,75}\right)$, conforme SIGNORETTI et al. (1999b), pela concentração de EM ( $\mathrm{kcal} / \mathrm{kg}$ de MS) da dieta usada em cada tratamento.
Posteriormente, calculou-se a concentração de energia líquida para mantença (ELm), na dieta de cada tratamento, dividindo-se a produção de calor dojejum (110,46 $\mathrm{kcal} / \mathrm{kg}^{0,75}$ ), estimada para o consumo de EM igual a zero, pelo consumo de MS para manter o equilíbrio de energia, expresso em $\mathrm{gMS} / \mathrm{kg}^{0,75}$.

O cálculo de energia líquida do ganho (ELg), para cada tratamento, foi efetuado subtraindo-se o consumo voluntário de MS (gMS $/ \mathrm{kg}^{0,75}$ ) do consumo de MS suficiente, para manter o equilíbrio de energia (gMS/ $\mathrm{kg}^{0,75}$ ). A concentração de ELg foi calculada dividindose o balanço energético diário (energia retida por dia), em $\mathrm{kcal} / \mathrm{kg}^{0,75}$, pelo consumo de MS acima das necessidades de mantença, expresso em $\mathrm{gMS} / \mathrm{kg}^{0,75}$.

As exigências de EM foram obtidas dividindo-se as ELm e ELg pelas eficiências de utilização da EM, para mantença $(\mathrm{km})$ e ganho $(\mathrm{kf})$, respectivamente.

As exigências de nutrientes digestíveis totais (NDT) foram obtidas pela divisão das exigências de EM por 0,82, obtendo-se a energia digestível (ED). Posteriormente, considerando-se que $1 \mathrm{~kg}$ de NDT equivale a 4,409 Mcal de ED, calcularam-se as exigências de NDT $(\mathrm{kg})$ dividindo-se as exigências de ED por 4,409 (NRC, 1984).

A eficiência de utilização de EM para ganho de peso foi estimada utilizando-se os dados obtidos no presente estudo e os encontrados por ARAÚJO (1997). Ajustou-se equação de regressão da concentração de EL das dietas, em função do teor de EM das dietas, conforme a metodologia descrita por GARRETT (1980).

Realizaram-se, também, estimativas das exigências de EM utilizando-se a equação abaixo, segundo o AFRC (1993):

em que

$$
\mathrm{EM}=(\mathrm{ELm} / \mathrm{K}) \cdot \ln (\mathrm{B} /(\mathrm{B}-\mathrm{R}-1)),
$$

ELm = energia líquida de mantença, determinada neste estudo;

$\mathrm{K}=\mathrm{km} \cdot \ln (\mathrm{km} / \mathrm{kf})$;

$\mathrm{km}=0,35 \mathrm{qm}+0,503$;

$\mathrm{kf}=0,78 \mathrm{qm}+0,006$;

$\mathrm{qm}=\mathrm{M} / 18,8$;

$\mathrm{M}=\mathrm{MJ}$ de $\mathrm{EM} / \mathrm{kg}$ de MS da dieta. Utilizaram-se no cálculo os valores de 12,47; 11,55; 11,04 e 10,59 MJ de EM porkg de MS, respectivamente, para 2,98;2,76;2,64 e 2,53 Mcal $/ \mathrm{kg}$ de $\mathrm{MS}$, determinados neste estudo;

$\mathrm{B}=\mathrm{km} /(\mathrm{km}-\mathrm{kf})$;

$\mathrm{R}=\mathrm{ELg} / \mathrm{ELm}$, determinados neste estudo.

As exigências de proteína metabolizável (PMmp) foram estimadas de acordo com a metodologia do AFRC (1993), pela soma da proteína metabolizável para mantença $(\mathrm{PMm})$ e da exigência líquida de 
proteína para ganho (PLg), estimada considerandose o fator de eficiência de retenção de proteína para ganho de 0,59. Adotou-se nível de segurança de 5\%.

Assim,

$$
\text { PMmp }=2,3 \mathrm{~kg}^{0,75}+\mathrm{PLg} / 0,59
$$

PLg foi determinada neste estudo.

Utilizando-se as eficiências de utilização de PM obtidas pela equação proposta pelo NRC (1996), calcularam-se as exigências de PM para ganho (PMg), considerando-se as exigências de PLg obtidas neste estudo.

Se o peso corporal equivalente de abate for $<300$ $\mathrm{kg}$, a eficiência de utilização da PM é igual a 49,20\%, sendo, portanto, calculado pela seguinte equação:

$\%$ Eficiência da PM para ganho = 83,4-(0,114.PCEA), em que

PCEA = peso corporal equivalente de abate, em kg

$\mathrm{O}$ requerimento de mantença de $\mathrm{PM}$ foi calculado utilizando-se a seguinte equação:

$$
\mathrm{PMm}=3,8 \mathrm{~kg}^{0,75} \text { (gPM/dia). }
$$

Somando-se os requerimentos de $\mathrm{PMm}$ e $\mathrm{PMg}$, foram obtidas as necessidades de PM para faixa de peso vivo dos animais utilizados no presente trabalho.

\section{Resultados e Discussão}

Na Tabela 1 são mostrados os teores de nutrientes digestíveis totais (NDT), as concentrações de energia metabolizável (EM) e os valores calculados de ELm, ELg, $\mathrm{km}$ e $\mathrm{kf}$ dos dados obtidos por SIGNORETTI et al. (1999 a,b). O NRC (1984) estima os valores de ELm e ELg de uma dieta com concentração de EM de $2,8 \mathrm{Mcal} / \mathrm{kg}$ de MS, em 1,86 e 1,22 Mcal $/ \mathrm{kg}$ de MS, respectivamente. O valor para ELm é $8,77 \%$ superior, enquanto para ELg é semelhante ao obtido neste trabalho.

As exigências diárias para mantença de EM, expressas em Mcal, e de NDT, expressas em kg, estimadas no presente trabalho para animais na faixa de peso vivo variando de 75 a $300 \mathrm{~kg}$, encontram-se na Tabela 2. Considerando-se um animal de $300 \mathrm{~kg}$ de $\mathrm{PV}$, os resultados mostraram que as exigências de EM para mantença foram de 11,56 Mcal/dia. Este valor é $29,31 \%$ superior ao valor encontrado por ARAÚJO (1997), que trabalhou com animais mestiços Holandês x Zebu, em faixa etária semelhante à do presente trabalho.

São apresentados nas Tabelas 3 e 4 os respectivos valores das exigências de EM, em Mcal, e NDT, em $\mathrm{kg}$, por quilograma de ganho de peso corporal vazio (GPCVZ), obtidas para bezerros da raça Holandesa recebendo níveis crescentes de volumoso nas dietas, bem como tomadas em conjunto (Média geral), na faixa de peso vivo (PV) de 75 a $300 \mathrm{~kg}$.

As exigências de EM (Mcal) e NDT (kg), por unidade de peso ganho, aumentaram, à medida que se elevou o peso corporal do animal, para todos os níveis de volumoso, bem como para média geral. Estes resultados são concordantes com os obtidos por ARAÚJO (1997) e FERREIRA (1997). Da mesma forma, o AFRC (1993) mostrou aumento nas exigências de EM de 35 para $69 \mathrm{MJ} /$ dia, para ganho de 1 quilograma, à medida que o peso se elevou de 100 para $300 \mathrm{~kg}$, em bovinos não-castrados.

As exigências diárias de EM (Mcal) e NDT ( $\mathrm{kg})$, para mantença, para ganho de $1 \mathrm{~kg}$ de PCVZ e total, para bezerros da raça Holandesa, com peso vivo variando de 75 a $300 \mathrm{~kg}$ obtidas pela média geral, encontram-se na Tabela 5. A exigência diária de EM, considerando-se o total (mantença + ganho de $1 \mathrm{~kg}$ de PCVZ), para um animal de $300 \mathrm{~kg}$ de PV, é de 18,12 $\mathrm{Mcal} /$ dia. Este valor é $12,97 \%$ inferior e $14,32 \%$ superior, respectivamente, aos valores obtidos por

Tabela 1 - Teores de nutrientes digestíveis totais (NDT) e concentrações de energia metabolizável (EM) para os níveis de volumoso das dietas (NV\%), concentração de energia líquida para mantença (ELm) e ganho de peso (ELg), calculadas para cada nível de volumoso, e eficiência de utilização da EM para mantença $(\mathrm{km})$ e ganho $(\mathrm{kf})$, para cada nível de volumoso na dieta

Table 1 - Total digestible nutrients (TDN) contents and metabolizable energy (ME) concentrations for the forage levels in the diets (LF \%), concentration of net energy for maintenance (NEm ) and weight gain (NEg), calculated for each forage level, and ME efficiency utilization for maintenance $(\mathrm{km})$ and gain $(\mathrm{kf})$ for each

\begin{tabular}{|c|c|c|c|c|c|c|}
\hline \multirow[t]{2}{*}{$\begin{array}{l}\mathrm{NV}(\%) \\
L F\end{array}$} & \multirow[t]{2}{*}{$\begin{array}{c}\text { NDT }(\%) \\
T D N\end{array}$} & \multirow[t]{2}{*}{$\begin{array}{l}\mathrm{EM} \\
M E\end{array}$} & \multirow{2}{*}{$\begin{array}{c}\text { ELm } \\
\text { NEm } \\
\mathrm{Mcal} / \mathrm{kg} \mathrm{MS} \\
\text { Mcal/kg DM }\end{array}$} & \multirow[t]{2}{*}{$\begin{array}{l}\mathrm{ELg} \\
\mathrm{NEg}\end{array}$} & \multicolumn{2}{|c|}{$\begin{array}{c}\text { Eficiência (\%) } \\
\text { Efficiency }\end{array}$} \\
\hline & & & & & $\mathrm{km}$ & $\mathrm{kf}$ \\
\hline$\overline{10}$ & 82,00 & 2,98 & 1,85 & 1,36 & 0,62 & 0,46 \\
\hline 25 & 76,33 & 2,76 & 1,71 & 1,21 & 0,62 & 0,44 \\
\hline 40 & 73,33 & 2,64 & 1,64 & 1,06 & 0,62 & 0,40 \\
\hline 55 & 69,67 & 2,53 & 1,57 & 1,04 & 0,62 & 0,41 \\
\hline
\end{tabular}
forage level in the diet 
218 Rev. bras. zootec.

Tabela 2 - Exigências diárias de mantença de energia metabolizável (EM) e nutrientes digestíveis totais (NDT) para os diferentes pesos vivos (PV) e pesos corporais vazios (PCVZ)

Table 2 - Dailymaintenance requirements of metabolizable energy (ME) and digestible nutrients (TDN) for the different live weights ( $L W$ ) and empty body weights (EBW)

\begin{tabular}{lccc}
\hline $\mathrm{PV}(\mathrm{kg})$ & $\begin{array}{c}\mathrm{PCVZ}(\mathrm{kg}) \\
E B W\end{array}$ & $\begin{array}{c}\text { EM (Mcal/dia) } \\
M E\end{array}$ & $\begin{array}{c}\text { NDT (Mcal/day) } \\
(\mathrm{kg} / \text { dia })\end{array}$ \\
\hline 75 & 62,78 & 3,97 & 1,10 \\
100 & 84,77 & 4,98 & 1,38 \\
150 & 128,76 & 6,81 & 1,88 \\
200 & 172,74 & 8,48 & 2,35 \\
250 & 216,72 & 10,06 & 2,78 \\
300 & 260,70 & 11,56 & 3,20 \\
\hline
\end{tabular}

ARAÚJO (1997) e ROCHA et al. (1997).

Em média, a exigência total de NDT (mantença + ganho de $1 \mathrm{~kg}$ de PCVZ), obtida para animais de $300 \mathrm{~kg}$ de PV, foi de 5,02 kg de NDT/dia. Este valor é $12,75 \%$ inferior e $14,61 \%$ superior, respectivamente, aos valores encontrados por ARAÚJO (1997) e
ROCHA et al. (1997), para bovinos de origem leiteira. Comparando-se os valores deste trabalho com os valores estimados pelo NRC (1989) e AFRC (1993), respectivamente, de 4,43 e 4,36 kg de NDT/dia, para animais de $300 \mathrm{~kg}$ de PV e ganho de $1 \mathrm{~kg} /$ dia, esses são, respectivamente, 13,32 e 15,14\% inferiores aos obtidos no presente trabalho. Contudo, a exigência total de NDT, em gramas por unidade de tamanho metabólico, decresceu com o aumento do peso corporal.

Ajustou-se equação de regressão relacionando as concentrações de energia líquida para ganho, em função das concentrações de energia metabolizável das dietas utilizadas no presente estudo, e as obtidas por ARAÚJO (1997), do tipo:

$\hat{\mathrm{Y}}=-110,229+122,710 \mathrm{EM}-45,2637 \mathrm{EM}^{2}+5,5869 \mathrm{EM}^{3}, \mathrm{R}^{2}=0,76$

Utilizando-se os valores de energia metabolizável das dietas experimentais de 2,98;2,76;2,64 e 2,53 $\mathrm{Mcal} / \mathrm{kg}$ de MS, respectivamente, para os níveis de volumoso nas dietas de 10, 25, 40 e 55\%, na equação supracitada, obtiveram-se os respectivos valores da eficiência de utilização de energia metabolizável para

Tabela 3 - Exigências de energia metabolizável (EM) para ganho de peso corporal vazio e em conjunto (Geral), para os diferentes pesos vivos (PV) e pesos corporais vazios (PCVZ)

Table 3 - Metabolizable energy (ME) requirements for empty body weight gain and in overall for the different live weights (LW) and empty body weights (EBW)

\begin{tabular}{|c|c|c|c|c|c|c|}
\hline \multirow[t]{2}{*}{$\begin{array}{l}\mathrm{PV}(\mathrm{kg}) \\
L W\end{array}$} & \multirow[t]{2}{*}{$\begin{array}{c}\mathrm{PCVZ}(\mathrm{kg}) \\
E B W\end{array}$} & \multicolumn{3}{|c|}{ Nível de volumoso (\%) } & & \multirow[b]{2}{*}{ Geral(Overall) } \\
\hline & & 10 & 25 & 40 & 55 & \\
\hline \multicolumn{7}{|c|}{ EM(Mcal/kg GPCVZ) } \\
\hline \multicolumn{7}{|c|}{$M E(M c a l / k g E B W G)$} \\
\hline 75 & 62,78 & 4,50 & 4,77 & 5,03 & 4,68 & 4,75 \\
\hline 100 & 84,77 & 4,91 & 5,09 & 5,30 & 5,00 & 5,08 \\
\hline 150 & 128,76 & 5,52 & 5,68 & 5,70 & 5,49 & 5,60 \\
\hline 200 & 172,74 & 6,00 & 6,02 & 6,00 & 5,85 & 5,97 \\
\hline 250 & 216,72 & 6,41 & 6,34 & 6,25 & 6,17 & 6,29 \\
\hline 300 & 260,70 & 6,76 & 6,61 & 6,45 & 6,42 & 6,56 \\
\hline
\end{tabular}

Tabela 4 - Exigências de nutrientes digestíveis totais (NDT) para ganho de peso corporal vazio e em conjunto (Geral), para os diferentes pesos vivos (PV) e pesos corporais vazios (PCVZ)

Table 4 - Total digestible nutrients (TDN) requirements for empty body weight gain and in overall for the different live weights (LW) and empty body weights (EBW)

\begin{tabular}{|c|c|c|c|c|c|c|}
\hline \multirow[t]{2}{*}{$\begin{array}{l}\overline{\mathrm{PV}}(\mathrm{kg}) \\
L W\end{array}$} & \multirow[t]{2}{*}{$\begin{array}{c}\text { PCVZ }(\mathrm{kg}) \\
E B W\end{array}$} & \multicolumn{3}{|c|}{ Nível de volumoso (\%) } & & \multirow[b]{2}{*}{ Geral (Overall) } \\
\hline & & 10 & 25 & 40 & 55 & \\
\hline \multicolumn{7}{|c|}{ NDT (kg/kgGPCVZ) } \\
\hline \multicolumn{7}{|c|}{$T D N(\mathrm{~kg} / \mathrm{kg} E B W G)$} \\
\hline 75 & 62,78 & 1,24 & 1,32 & 1,39 & 1,30 & 1,31 \\
\hline 100 & 84,77 & 1,36 & 1,42 & 1,47 & 1,38 & 1,41 \\
\hline 150 & 128,76 & 1,53 & 1,57 & 1,58 & 1,52 & 1,55 \\
\hline 200 & 172,74 & 1,66 & 1,67 & 1,66 & 1,62 & 1,65 \\
\hline 250 & 216,72 & 1,77 & 1,75 & 1,73 & 1,71 & 1,74 \\
\hline 300 & 260,70 & 1,87 & 1,83 & 1,78 & 1,78 & 1,82 \\
\hline
\end{tabular}


SIGNORETTI et al.

Tabela 5 - Exigências diárias de energia metabolizável (EM) e nutrientes digestíveis totais (NDT), para pesos vivos variando de 75 a $300 \mathrm{~kg}$ e pesos corporais vazios (PCVZ) de 62,78 a 260,70 kg

Table 5 - Daily metabolizable (ME) and total digestible nutrients (TDN) requirements for live weights from 75 to $300 \mathrm{~kg}$ and empty body weights from 62.78 to $260.70 \mathrm{~kg}$

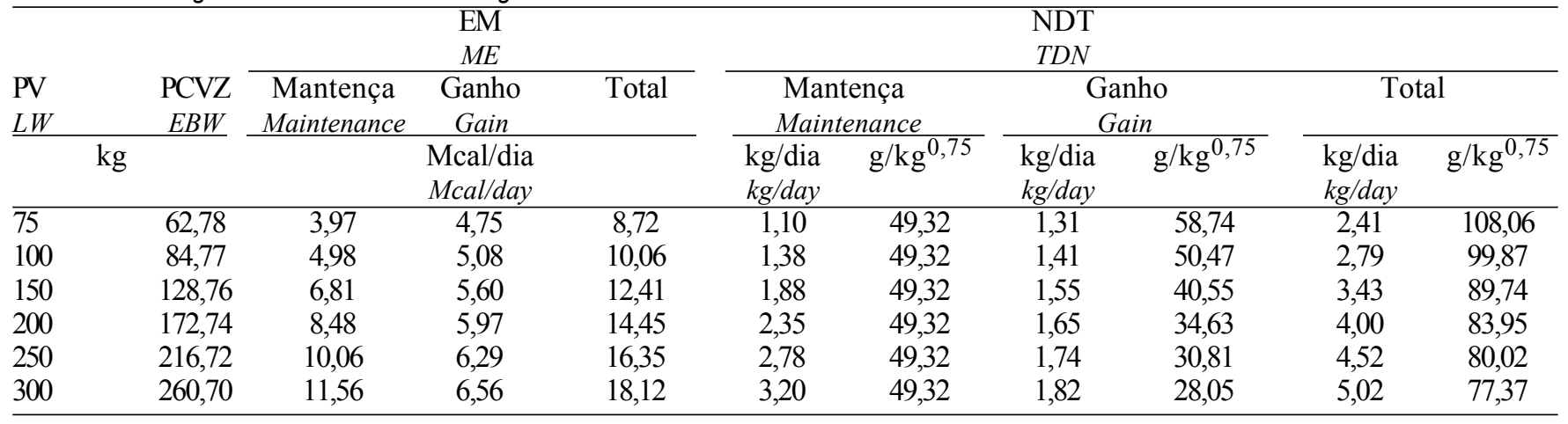

ganho (kf) de 0,$45 ; 0,40 ; 0,40 ;$ e 0,39 . Estes valores são semelhantes aos verificados no presente trabalho (Tabela 1) e inferiores aos estimados pelas equações do AFRC (1993), de 0,52; 0,49; 0,47; e 0,44, respectivamente, para os níveis de $10,25,40$ e $55 \%$ de volumoso na dieta.

Utilizando-se o modelo matemático proposto pelo AFRC (1993), para o cálculo das exigências de energia metabolizável, foram feitas estimativas com os dados médios obtidos no presente trabalho.

$\mathrm{Na}$ Tabela 6 são apresentadas as exigências médias de EM (Mcal/dia) e NDT (kg/dia), para bezerros da raça Holandesa com pesos vivos (PV) variando de 75 a $300 \mathrm{~kg}$ e pesos corporais vazio (PCVZ) de 62,78 a 260,70 kg, usando-se nível de segurança de $5 \%$.

Considerando-se os valores obtidos no presente trabalho (Tabela 5), utilizando a metodologia do NRC (1984), para as exigências de EM (Mcal/dia) para animais com 100 (10,06 Mcal), 200 (14,45 Mcal) e 300 (18,12 Mcal) quilogramas de peso vivo, quando comparadas com os valores correspondentes estimados pelas equações propostas pelo AFRC (1993), de 9,33; 13,05; e 16,23 Mcal, para animais com mesmo peso vivo, são, respectivamente, 7,$82 ; 10,73$; e $11,65 \%$ superiores.

Da mesma forma, para as exigências de NDT $(\mathrm{kg} / \mathrm{dia})$ obtidas no presente trabalho, calculadas a partir das exigências de EM, para animais com 100 $(2,79 \mathrm{~kg}), 200(4,00 \mathrm{~kg})$ e $300(5,02 \mathrm{~kg})$ quilogramas de peso vivo, quando comparadas com os valores correspondentes estimados pelas equações propostas pelo AFRC (1993), de 2,58; 3,61 e 4,49 kg, para animais com mesmo peso vivo são, respectivamente, 8,$14 ; 10,80$ e $11,80 \%$ superiores.
Adotando-se a metodologia do AFRC (1993), foram obtidas as estimativas de proteína metabolizável para atender aos requerimentos em nível de tecido (Tabela 7). Estas estimativas considerando animais de $300 \mathrm{~kg}$ de peso vivo, publicadas pelo AFRC (1993), foram $9,67 \%$ inferiores aos valores obtidos no presente trabalho.

A exigência de proteína metabolizável total, considerando-se um animal de $300 \mathrm{~kg}$ de PV, é de 500,11 $\mathrm{g} /$ dia. Este valor é $19,67 \%$ superior ao valor encontrado por ROCHA et al. (1997), que utilizaram a mesma metodologia e animais castrados de origem leiteira. Esta diferença pode ser explicada, em parte, pela condição sexual dos animais, pois animais castrados são menos exigentes em proteína que os animais nãocastrados (GEAY, 1984).

Tabela 6 - Exigências diárias de energia metabolizável(EM) e nutrientes digestíveis totais (NDT), para diferentes pesos vivos (PV) e pesos corporais vazios (PCVZ), calculadas de acordo com o AFRC (1993)

Table 6 - Daily metabolizable (ME) and total digestible nutrients (TND) requirements for live weights (LW) and empty body weights (EBW), calculated according to AFRC (1993)

\begin{tabular}{lccc}
\hline $\mathrm{PV}(\mathrm{kg})$ & $\begin{array}{c}\mathrm{PCVZ}(\mathrm{kg}) \\
L W\end{array}$ & $\begin{array}{c}\mathrm{EM}(\mathrm{Mcal} / \mathrm{dia}) \\
M E(\text { Mcal/day })\end{array}$ & $\begin{array}{c}\text { NDT }(\mathrm{kg} / \mathrm{dia}) \\
(T D N, \mathrm{~kg} / \text { day })\end{array}$ \\
\hline 75 & 62,78 & 8,28 & 2,29 \\
100 & 84,77 & 9,33 & 2,58 \\
150 & 128,76 & 11,28 & 3,12 \\
200 & 172,74 & 13,05 & 3,61 \\
250 & 216,72 & 14,70 & 4,06 \\
300 & 260,70 & 16,23 & 4,49 \\
\hline
\end{tabular}


Tabela 7 - Exigências líquidas (PLm) e metabolizável (PMm) de proteína para mantença, exigências líquidas $(\mathrm{PLg})$ e metabolizável $(\mathrm{PMg})$ para ganho de $1 \mathrm{~kg}$ de $\mathrm{PV}$ e proteína metabolizável total (PMt), para os diferentes pesos vivos (PV) e pesos corporais vazios (PCVZ), calculadas pelo AFRC (1993)

Table 7 - Metabolizable (MPm) and net (LPm) protein for maintenance requirements and metabolizable (MPg) and net $(L P g)$ requirements for gain of $1 \mathrm{~kg}$ of live weights $(L W)$ and total metabolizable (MPt) protein for the different live weights(LW) and empty body weights (EBW) calculated according to AFRC (1993)

\begin{tabular}{lcccccc}
\hline PV $(\mathrm{kg})$ & PCVZ(kg) & PLm & PMm & PLg & PMg & PMT \\
$L W$ & $E B W$ & $L P m$ & $M P m$ & $L P g$ & $M P g$ & $M P t$ \\
\cline { 2 - 6 } & & 9,38 & 58,62 & 179,84 & 304,81 & 381,60 \\
75 & 62,78 & 11,64 & 72,73 & 180,54 & 306,00 & 397,67 \\
100 & 84,77 & 15,77 & 98,56 & 181,53 & 307,68 & 426,55 \\
150 & 128,76 & 122,32 & 182,22 & 308,85 & 452,73 \\
200 & 172,74 & 19,57 & 144,60 & 182,76 & 309,76 & 477,08 \\
250 & 216,72 & 23,14 & 165,79 & 183,20 & 310,51 & 500,11 \\
300 & 260,70 & 26,53 & &
\end{tabular}

Tabela 8 - Exigências de proteína metabolizável (PMm) para mantença e ganho $(\mathrm{PMg})$ de $1 \mathrm{~kg}$ de PV e proteína metabolizável total (PMt), para os diferentes pesos vivos (PV) e pesos corporais vazios (PCVZ), calculadas pelo NRC (1996)

Table 8 - Metabolizable protein for maintenance (MPm) and gain $(\mathrm{MPg})$ of $1 \mathrm{~kg}$ of live weights $(L W)$ and total metabolizable (MPt) protein requirements, for the different $L W$ and empty body weights (EBW) calculated by NRC (1996)

\begin{tabular}{|c|c|c|c|c|}
\hline \multirow{4}{*}{$\begin{array}{l}\mathrm{PV}(\mathrm{kg}) \\
L W\end{array}$} & & \multirow{3}{*}{$\begin{array}{l}\mathrm{PMg} \\
\mathrm{MPg}\end{array}$} & \multirow{3}{*}{$\begin{array}{l}\text { PMt } \\
M P t\end{array}$} \\
\hline & PCVZ $(\mathrm{kg})$ & PMm & & \\
\hline & $E B W$ & $M P m$ & & \\
\hline & & \multicolumn{3}{|c|}{ g/dia (g/day) } \\
\hline$\overline{75}$ & 62,78 & 96,85 & 235,95 & 332,80 \\
\hline 100 & 84,77 & 120,17 & 244,93 & 365,10 \\
\hline 150 & 128,76 & 162,87 & 264,27 & 427,14 \\
\hline 200 & 172,74 & 202,10 & 286,15 & 488,25 \\
\hline 250 & 216,72 & 238,91 & 311,56 & 550,47 \\
\hline 300 & 260,70 & 273,92 & 341,47 & 615,39 \\
\hline
\end{tabular}

Adotando-se a metodologia do NRC (1996), foram obtidas estimativas das exigências de proteína metabolizável para mantença e ganho de peso, para bezerros da raça Holandesa (Tabela 8).

Considerando-se os valores obtidos pela metodologia do AFRC (1993), para estimativas das exigências de proteína metabolizável total (g/dia), para animais de $100(397,67 \mathrm{~g}), 200(452,73 \mathrm{~g})$ e 300 $(500,11 \mathrm{~g})$ quilogramas de peso vivo, quando comparadas com os valores estimados pela metodologia do NRC (1996), de 365,10; 488,25 e 615,39 g/dia, para animais com mesmo peso vivo, são, respectivamente, $8,92 \%$ superiores e 7,85 e $23,05 \%$ inferiores. Estas diferenças entre as duas metodologias supracitadas devem-se à menor exigência de PM para mantença adotada pelo AFRC (1993), em relação à utilizada pelo NRC (1996).

\section{Conclusões}

As exigências de EM (Mcal) e NDT ( $\mathrm{kg}$ ), por unidade de peso ganho, aumentaram, à medida que se elevou o peso corporal dos animais, para todos os níveis de volumoso.

As exigências médias totais de EM e NDT para animais de 100,200 e $300 \mathrm{~kg}$ de peso vivo foram de 10,$06 ; 14,45$ e $18,12 \mathrm{Mcal} / \mathrm{dia}$ e 2,$79 ; 4,00$ e $5,02 \mathrm{~kg} /$ dia, respectivamente.

As eficiências de utilização de EM para ganho (kf) foram estimadas em 0,$45 ; 0,40 ; 0,40$ e 0,39, respectivamente, para as concentrações de 2,98; 2,76; 2,64 e 2,53 Mcal/kg de MS, obtidas para níveis de $10,25,40$ e $55 \%$ de volumoso nas dietas.

As estimativas de exigências de energia metabolizável e nutrientes digestíveis totais pela metodologia do sistema americano, para um animal de $300 \mathrm{~kg}$ de peso vivo, foram, respectivamente, 11,65 e 11,80\% superiores aos valores estimados pela metodologia proposta pelo sistema britânico.

As estimativas de exigências de proteína metabolizável pela metodologia do sistema britânico, para um animal de $300 \mathrm{~kg}$ de peso vivo, foram $23,05 \%$ inferiores aos valores estimados pela metodologia do sistema americano. 


\section{Referências Bibliográficas}

AGRICULTURAL AND FOOD RESEARCH COUNCIL AFRC., 1993. Energy and protein requirements of ruminants. Wallingford: Commonwealth Agricultural Bureaux International. $159 \mathrm{p}$.

ARAÚJO, G.G.L. Consumo, digestibilidade, desempenho, composição corporal e exigências nutricionais de bezerros alimentados com dietas contendo diferentes níveis de volumoso. Viçosa, MG:UFV, 1997. 107 p. Tese (Doutorado em Zootecnia) - Universidade Federal de Viçosa, 1997.

COELHO DA SILVA, J.F., LEÃO, M.I. 1979. Fundamentos de nutrição dos ruminantes. Piracicaba:Livroceres. 380p.

FERREIRA, M.A. Desempenho, exigências nutricionais e eficiência de utilização da energia metabolizável para ganho de peso de bovinos F1 Simental x Nelore. Viçosa, MG:UFV, 1997. 97p. Tese (Doutorado em Zootecnia) - Universidade Federal de Viçosa, 1997.

GARRETT, W.N. 1980. Factors influencing energetic efficiency of beef production. J. Anim. Sci., 51(6):1434 - 1440.

GEAY, Y. Energy and protein utilization in growing cattle. $J$. Anim. Sci., 58(3):766 - 778, 1984.

HARRIS, L.F. 1970. Nutrition research technique for domestic and wild animal. v.1, Logan, Utah, paginação descontínua.

NATIONAL RESEARCHCOUNCIL-NRC. Nutrient requirements of beef cattle. 6.ed. Washington, DC, $1984.90 \mathrm{p}$.

NATIONAL RESEARCH COUNCIL - NRC. 1989. Nutrient requirements of dairy cattle. 6.ed. Washington, D.C. 157 p.

NATIONAL RESEARCH COUNCIL - NRC. 1996. Nutrient requirements of beef cattle. 7.ed. Washington, D.C: National Academy Press. 242 p.

OLD, C.A., GARRETT, W.N. 1984. Efficiency of feed energy utilization for protein and fat gain in Hereford and Charolais steers. J. Anim. Sci., 60(3):766-771.
ROCHA, E.O., FONTES, C.A.A., CASTRO, A.C.G. et al. Exigências nutricionais e características produtivas de novilhos de origem leiteira. 2. Exigências de energia e proteína para mantença e ganho de peso In: REUNIÃO ANUAL DA SOCIEDADE BRASILEIRA DE ZOOTECNIA, 34, Juiz de Fora, MG, 1997. Anais... Juiz de Fora: SBZ, 1997. p. 6-8.

SIGNORETTI, R.D., COELHO DA SILVA, J.F., VALADARES FILHO, S.C. et al. 1999b. Consumo e digestibilidade aparente em bezerros da raça Holandesa alimentados com dietas contendo diferentes níveis de volumoso. Rev. bras. zootec., 28(1):169-177.

SIGNORETTI, R.D., COELHO DA SILVA, J.F., VALADARES FILHO, S.C. et al., 1999c. Composição corporal e exigências líquidas de energia e de proteína de bezerros da raça Holandesa alimentados com dietas contendo diferentes níveis de volumoso. Rev. bras. zootec., 28(1):195-204.

VALADARES FILHO, S.C. 1997. Digestão pós-ruminal de proteínas e exigências de aminoácidos para ruminantes. In: TEIXEIRA, J.C. (Ed). SIMPÓSIO INTERNACIONAL DE DIGESTIBILIDADE EM RUMINANTES, 1997, Lavras, MG. Anais... Lavras: FAEPE. p.87 - 113.

VAN SOEST, P.J. 1994. Nutritional ecology of the ruminants. 2.ed. London: Constock Publishing Associates, USA. 476p.

WALDO, D.R., GLEN, B.P. 1981. Foreign systems for meeting the protein requirements of ruminants. II. Meeting protein requirements of cattle. In: OWENS, F.N. (Ed). Proc. protein requirements for cattle: Symposium, 109: 269-309.

Recebido em: 08/04/98

Aceito em: 20/08/98 